\title{
FATORES DETERMINANTES PARA A ADOCÃO DE PADRÕES INTERNACIONAIS DE CONTABILIDADE NO BRASIL: UMA INVESTIGAÇÃO EM EM- PRESAS PÚBLICAS E PRIVADAS DO SETOR DE ENERGIA ELETRICA
}

\section{DETERMINANTS OF INTERNATIONAL CONVERGENCE OF ACCOUNTING STANDARDS IN BRAZIL: AN INVESTIGATION IN THE PRIVATE AND PUBLIC COMPANIES ELECTRICITY SECTOR}

\author{
Vinícius Costas da Silva Zonatto ${ }^{a}$; Alexandre Corrêa dos Santos ${ }^{b}$; \\ Moacir Manoel Rodrigues Junior ${ }^{c}$; Francisco Antonio Bezerra ${ }^{d}$ \\ ${ }^{a}$ Professor Titular da Faculdade Dom Alberto, DOM ALBERTO; Doutorado em andamento em Ciências Contábeis e Administração pela \\ Fundação Universidade Regional de Blumenau, FURB; Mestrado em Ciências Contábeis pela Fundação Universidade Regional de Blumenau, FURB, \\ Blumenau, SC - Brasil; E-mail: viniciuszonatto@gmail.com \\ ${ }^{b}$ Sócio Administrador do R. Volponi Contadores Associados, R. VOLPONI; Mestrado em andamento em Ciências Contábeis pela Fundação Universidade Re- \\ gional de Blumenau, FURB; Graduado em Ciências Contábeis pela Faculdade Estadual de Filosofia Ciências Letras de Cornélio Procópio, FAFICOP, \\ Blumenau,SC-Brasil; E-mail: alexandrecorrea@al.furb.br \\ ${ }^{c}$ Mestrado em andamento em Ciências Contábeis pela Universidade Regional de Blumenau, FURB; Graduado em Matemática pela Universidade Regional de \\ Blumenau,FURB, Blumenau, SC-Brasil; E-mail: mmrodrigues@al.furb.br \\ ${ }^{d}$ Professor da Fundação Universidade Regional de Blumenau, FURB; Doutorado em Controladoria e Contabilidade pela Universidade de São Paulo, USP; \\ Blumenau, SC-Brasil; E-mail: fbezerra@furb.br
}

\section{Resumo}

Este estudo concentra-se nos fatores que determinam a adoção de um processo de convergência contábil nas organizações. O objetivo central do estudo é identificar, dentro de um conjunto de características da empresa, aquelas que melhor explicam a aderência às normas internacionais de empresas do Setor Elétrico listadas na BM\&F Bovespa. A metodologia utilizada na pesquisa é caracterizada como um estudo exploratório, com abordagem quantitativa dos dados. Para que fosse possível concluir sobre o objeto de estudo, adotou-se o Índice de Observância às Práticas de Convergência (IOPC), construído a partir do estabelecimento dos novos dispositivos legais (CPC 13 e 37 R1) e o estudo de Lima et al. (2010). Com base no IOPC e usando os indicadores contábeis descritos na questão objeto de estudo, utilizou-se da Teoria dos Conjuntos Aproximativos para verificar a hipótese de existência de um núcleo declaratório contábil que melhor explicasse a aderência às normas contábeis. Os resultados auferidos demonstram que os índices de Tamanho, Necessidade de Financiamento, Endividamento Total, Imobilização e Rentabilidade do Patrimônio Líquido são os índices que melhor explicam a aderência às normas internacionais de contabilidade nas empresas em estudo. O item Origem do Controle não obteve sucesso na explicação da adoção dos novos dispositivos legais das empresas pesquisadas.

Palavras-chave:Convergência contábil; IFRS; Disclosure.

\section{Abstract}

This study focuses on the area of Accounting Theory, more specifically related to the factors that determine the convergence in accounting organizations. The main objective of the study is to identify which indicators among: Source Control, Size, Borrowing, Total Debt, Asset Equity and Return on Equity, best explain the adherence to international standards for electric utility company listed on the BM \& F Bovespa. The methodology used in research is characterized as an exploratory study with a quantitative data approach. For it was possible to conclude about the object of study, we adopted the Compliance Practices Index Convergence (IOPC), built from the establishment of new legal provisions (CPC 13:37 R1) and the study of Lima et al. (2010). Based on the IOPC, and using indicators of accounting described in the goal, we used the approximate theory of sets to verify the hypothesis of a declaratory core book that best explain the adherence to the accounting standards. Actual results show that rates of size, financing needs, Total Debt, Fixed Assets and Return on Equity, are the indices that best explain the adherence to international accounting standards in the companies under study. The Source Control item has not succeeded in explaining the adoption of new legal provisions of the companies surveyed.

Keywords: Accounting convergence; IFRS; Disclosure. 


\section{INTRODUÇÃO}

Recentes crises ocorridas em grandes corporações, com impacto mundial, trazem à tona novos debates sobre a necessidade de harmonização das práticas contábeis, a fim de proporcionar uma maior qualidade dos relatórios financeiros das organizações. No Brasil, o processo de convergência contábil aos padrões internacionais teve inicio com a publicação da Lei 11.638/2007 e demais pronunciamentos do CPC (Comitê de Pronunciamentos Contábeis).

Dentre os possíveis benefícios, para as empresas brasileiras, da convergência aos padrões internacionais, estão à provável redução do custo de captação e uma maior valorização das ações no mercado de capitais (SCHROEDER, CLARK e CAHEY, 2001). Por outro lado, na percepção dos usuários externos da informação contábil, acredita-se que, com a adoção de tais práticas, haverá uma maior qualidade dos informes financeiros, bem como um melhor disclosure.

Logo, face a estas vantagens e benefícios que podem ser obtidos pelas empresas com o processo de convergência, pode-se assumir uma premissa de que todas as empresas brasileiras que negociam ações no mercado de capitais deveriam assimilar e divulgar seus informes financeiros, em conformidade com as deliberações da CVM e os pronunciamentos do CPC; uma vez que tais práticas proporcionariam benefícios diretos às mesmas.

Contudo, estudos recentes indicam que apenas empresas que recebem incentivos adotam práticas de disclosure voluntário (HANDA e LINN, 1993; BAUMANN e NIER, 2004; BALL e SHIVAKUMAR, 2005; BURGSTAHLER, HAIL e LEUZ, 2006). No Brasil, Lima et. al. (2010, p. 13), num estudo compreendendo uma amostra de 50 empresas listadas na Bolsa de Valores de São Paulo, pertencentes à carteira Ibovespa entre Setembro e Dezembro de 2009, identificaram que apenas "empresas maiores, mais expostas ao mercado internacional, e que possuem maiores necessidades de financiamento, são mais propensas a adotarem os novos dispositivos".

Neste contexto, este estudo busca identificar: Quais as características, dentre a origem de controle, tamanho, necessidade de financiamento, endividamento total, imobilização do Patrimônio Líquido e rentabilidade do Patrimônio Líquido, melhor explicam a aderência às normas internacionais de empresas do Setor Elétrico listadas na BM\&F Bovespa?

O objetivo central da pesquisa é identificar dentro de um conjunto de características da empresa aquelas que melhor explicam a aderência às normas internacionais de empresas do Setor Elétrico listadas na BM\&F Bovespa.

Tendo em vista que os BRGAAPs postergaram a obrigatoriedade de adoção dos padrões internacionais de contabilidade, buscou-se a luz da teoria do disclosure voluntário, identificar se empresas do setor elétrico, listadas na BM\&F Bovespa, aderiram antecipadamente, de forma voluntária, as novas normas contábeis, antes da data final de sua obrigação. Da mesma forma, considerando-se os achados de estudos anteriores, os quais indicam que incentivos econômicos influenciam o disclosure voluntário das organizações, buscou-se identificar os fatores que melhor explicam a adoção de tais práticas.

De modo mais específico, buscou-se nesse estudo: i) verificar o nível de convergência das empresas pesquisadas às normas internacionais de contabilidade; ii) analisar entre as variáveis de Origem de Controle, Ativo Total, Necessidade de Financiamento, Endividamento 
Total, Imobilização do Patrimônio Líquido e Rentabilidade do Patrimônio Líquido, qual melhor explica a adoção dos dispositivos por parte das empresas pesquisadas; e, iii) averiguar a existência de um núcleo declaratório contábil na predição da aderência as normas internacionais.

Shin (1994) comenta que em momentos de crise nos mercados, os órgãos reguladores intensificam suas políticas de exigência do disclosure corporativo. No entanto, pesquisas indicam que algumas organizações divulgam apenas informações que acreditam que possam lhes proporcionar maiores benefícios, ou, informações de acordo com interesses específicos (BOTOSAN, 1997; SENGUPTA, 1998; DYE, 2001; VERRECHIA, 2001; GUAY e VERRECHIA, 2007).

Nesta perspectiva, diversos estudos (COSTA, GOLDNER e GALDI, 2007; MURCIA, 2009; ROVER et al., 2009; CRUZ e LIMA, 2010; LIMA et al., 2010) foram desenvolvidos no Brasil, inserindo as variáveis investigadas nesta pesquisa, com o intuito de identificar quais destes indicadores melhor explicam as práticas de disclosure corporativo das empresas brasileiras de capital aberto que negociam ações na BM\&F Bovespa. Em alguns casos, pôde-se verificar que é possível explicar o disclosure das organizações, por meio destas variáveis.

Desta forma, a aplicação proposta para a realização deste estudo é a investigação sob as práticas contábeis relacionadas ao processo de convergência aos padrões internacionais, de empresas brasileiras de capital aberto do setor de energia elétrica. Por meio do estabelecimento de uma métrica, pretende-se identificar o Índice de Observância às Práticas de Convergência (IOPC) das empresas objeto de estudo, e, a seguir, identificar os fatores que melhor explicam as práticas adotadas.

A metodologia utilizada na pesquisa é caracterizada como um estudo exploratório, com abordagem quantitativa dos dados. O IOPC adotado no estudo é construído a partir do estabelecimento dos novos dispositivos legais (CPC 13 e 37 R1) e a pesquisa desenvolvida por Lima et al. (2010). Assim sendo, pretende-se verificar se os incentivos econômicos destacados pelos autores, também influenciaram na adoção dos novos dispositivos legais por parte das empresas do setor de energia elétrica.

O trabalho justifica-se pela escassez de estudos com esta abordagem, sua relevância e a atualidade do tema, estando estruturado da seguinte forma: Inicialmente apresenta-se a fundamentação teórica da pesquisa. A seguir, as hipóteses, o método e os procedimentos do estudo. Por fim são apresentados os resultados e as considerações finais do trabalho.

\section{FUNDAMENTAÇÃO TEÓRICA}

\subsection{Adoção das normas internacionais de contabilidade (Lei 11638/2007, CPC 13 e 37 R1)}

A deliberação CVM n 647 de 02/12/2010 aprovou o Pronunciamento Técnico CPC 37 (R1) que trata da adoção inicial das normas internacionais de contabilidade no Brasil. De acordo com esta norma, fica revogada a Deliberação CVM n 609, de 22/12/2009 que tratava dentre outros assuntos da adoção obrigatória das IFRS para demonstrações consolidadas a partir de 2010. 
A entidade deve aplicar este Pronunciamento para suas primeiras demonstrações contábeis consolidadas elaboradas de acordo com as IFRSs para o exercício social iniciado em, ou depois de, $1^{\circ}$ de janeiro de 2010 (CPC 37, R1). No entanto, sua aplicação antecipada é permitida. A Deliberação CVM n ${ }^{\circ} 647 / 2010$, aplica-se às demonstrações consolidadas dos exercícios encerrados a partir de dezembro de 2010 e às demonstrações consolidadas de 2009 a serem divulgadas em conjunto com as demonstrações de 2010 para fins de comparação.

Segundo este pronunciamento técnico, para a adoção inicial das IFRSs, as organizações deverão adotar algumas medidas iniciais, bem como realizar algumas conciliações em suas demonstrações contábeis. O Quadro 1 sintetiza as principais medidas a serem observadas pelas companhias abertas após a adoção das IFRS.

\begin{tabular}{|c|c|}
\hline Medidas Iniciais & Conciliações Necessárias \\
\hline $\begin{array}{l}\text { - reconhecer todos os ativos e passivos cujo } \\
\text { reconhecimento seja requerido pelas IFRSs; }\end{array}$ & \multirow{2}{*}{$\begin{array}{l}\text { - efetuar as conciliações do patrimônio líquido divulgado pelos } \\
\text { critérios contábeis anteriores, em relação ao patrimônio líquido } \\
\text { de acordo com as IFRSs, para as seguintes datas: } \\
\checkmark \text { a data de transição para as IFRSs; e } \\
\checkmark \text { o fim do último período apresentado nas demonstrações } \\
\text { contábeis anuais mais recentes da entidade pelos critérios } \\
\text { contábeis anteriores. }\end{array}$} \\
\hline $\begin{array}{l}\text { - não reconhecer itens como ativos e passivos } \\
\text { se tal reconhecimento for vedado pelas } \\
\text { IFRSs; }\end{array}$ & \\
\hline $\begin{array}{l}\text { - reclassificar itens reconhecidos de acordo } \\
\text { com o conjunto de políticas contábeis que } \\
\text { vinha seguindo como um tipo de ativo, passivo } \\
\text { ou componente do patrimônio líquido, mas } \\
\text { que seja um tipo diferente de ativo, passivo ou } \\
\text { componente do patrimônio líquido de acordo } \\
\text { com as IFRSs; e, }\end{array}$ & $\begin{array}{l}\text { - efetuar a conciliação do resultado de acordo com as IFRSs } \\
\text { para o último período apresentado nas demonstrações contábeis } \\
\text { anuais mais recentes da entidade. O ponto de partida para essa } \\
\text { conciliação deve ser o resultado de acordo com os critérios } \\
\text { contábeis anteriores para o mesmo período. Se houver sido } \\
\text { divulgada a demonstração do resultado abrangente, o mesmo } \\
\text { é aplicável a ela; e, }\end{array}$ \\
\hline $\begin{array}{l}\text { - aplicar as IFRSs na mensuração d } \\
\text { ativos e passivos reconhecidos. }\end{array}$ & \multirow{2}{*}{$\begin{array}{l}\text { - efetuar as conciliações se a entidade reconheceu ou reverteu } \\
\text { qualquer perda por redução ao valor recuperável em sua } \\
\text { primeira vez na elaboração do balanço patrimonial de abertura } \\
\text { em IFRSs, as notas explicativas que a IAS } 36 \text { - Impairment of } \\
\text { Assets (Pronunciamento Técnico CPC } 01 \text { - Redução ao Valor } \\
\text { Recuperável de Ativos) teria requerido se a entidade tivesse } \\
\text { reconhecido tais perdas ou reversões no período iniciado na } \\
\text { data de transição para as IFRSs. }\end{array}$} \\
\hline $\begin{array}{l}\text { OBS.: A empresa deverá divulgar os impactos } \\
\text { da transição para IFRS (posição financeira, } \\
\text { desempenho financeiro e fluxos de caixa). }\end{array}$ & \\
\hline
\end{tabular}

Quadro 1: Síntese das recomendações CPC 37 (R1)

Fonte: adaptado do CPC 37 R1

Observa-se no Quadro 1 que as recomendações do CPC 37 (R1) levam em consideração a íntegra dos padrões internacionais de contabilidade, ou seja, as práticas das IFRS. Logo, verifica-se que há preocupação do CPC e da CVM em validar a aplicação das IFRS nas organizações brasileiras.

De acordo com Lima et al. (2010, p. 2), "apesar da obrigatoriedade da adoção de todos os recentes dispositivos contábeis pró-convergência no Brasil (excepcionado àqueles cuja legislação trouxe opção de postergar)", empresas brasileiras possuem características próprias, que influenciam a adoção ou postergação de implantação das IFRS. Segundo os autores, "o fato da legislação isentar a adoção imediata de certas práticas cria um aspecto interessante para a pesquisa no Brasil, permitindo um mix da análise entre voluntariedade e obrigatoriedade". 
Nesta perspectiva, estudos recentes foram desenvolvidos a fim de identificar aspectos favoráveis e desfavoráveis à convergência contábil aos padrões internacionais (IFRS). De acordo com Hail, Leuz e Wysocki (2009), a adoção das normas internacionais melhora a qualidade dos demonstrativos financeiros para os investidores externos. Covrig, Defond e Hung (2007) e Armstrong et al. (2010) explicam que a divulgação em IFRS reduz os custos relacionados à comparação das empresas entre diferentes países e mercados. Já Bradshaw, Bushee e Miller (2004) e Aggarwal, Klapper e Wysocki (2005) destacam que diferenças nos padrões contábeis podem impedir ou reduzir investimentos além de fronteiras.

Outra observação identificada em pesquisas recentes (BALL, 2006; NOBES, 2006; CHRISTENSEN, LEE e WALKER, 2007; DASKE et al., 2009), está relacionada ao impacto do processo de convergência no mercado de capitais. De acordo com os autores, o processo de convergência para um único padrão contábil internacional pode sequer ter algum efeito para o mercado de capitais, uma vez que as IFRSs equipam os gestores de substancial discricionariedade e, neste caso, os arranjos institucionais locais tendem a exercer importante papel (LIMA et al., 2010).

Para Lima et al. (2010, p. 10), "tais questionamentos buscam identificar se apenas mudanças obrigatórias nos dispositivos em si podem tornar os números contábeis mais comparáveis ou melhorar a atitude do gestor perante o compromisso com a transparência da informação contábil". Logo, verifica-se a importância das práticas de disclosure nas organizações. Mesmo que determinada empresa não esteja obrigada a divulgar determinado(s) evento(s), por meio do disclosure voluntário esta maximizaria a qualidade de sua informação. Assim sendo, tenderia a obter maior confiabilidade em seus ativos.

\subsection{O disclosure voluntário e os fatores que influenciam o disclosure nas organizações}

No mercado de capitais a divulgação das empresas é fundamental para o funcionamento de um mercado de capitais eficiente (HEALY e PALEPU, 2001). Por meio da divulgação das informações contábeis, as empresas se comunicam com os diversos agentes que adquirem ações da organização, investindo na mesma.

A informação contábil relaciona-se aos objetivos da contabilidade de mensurar o conjunto de eventos econômicos e comunicar os resultados das entidades às partes interessadas (YAMAMOTO e SALOTTI, 2006). De acordo com Stair (1998, p. 4), a informação pode ser compreendida como "um conjunto de fatos organizados de tal forma que adquirem valor adicional além do valor do fato em si".

No entanto, a divulgação difere da informação por seu conteúdo mais amplo e completo. Enquanto a informação traz o conteúdo, a divulgação compreende o conteúdo, a forma, a motivação e o veículo (YAMAMOTO e SALOTTI, 2006). Deste modo, pode-se perceber que além de divulgar, é necessário divulgar com qualidade a informação.

Nesta perspectiva Dantas, Zendersky e Niyama (2004, p. 2) advertem que, "para alcançar a transparência pretendida com o disclosure, a instituição deve divulgar informações qualitativas e quantitativas que possibilitem aos usuários formar uma compreensão das atividades desenvolvidas e dos seus riscos, observando aspectos de tempestividade, detalhamento e relevância necessários". 
Sob este aspecto o International Accounting Standarts Board - IASB (2001) recomenda que a informação contábil apresente quatro características qualitativas básicas: a compreensibilidade, a relevância, a confiabilidade e a comparabilidade. Tais características também são mencionadas pelo Comitê de Pronunciamentos Contábeis (CPC), no Pronunciamento da Estrutura Conceitual Básica da Contabilidade.

Uma das formas de se melhorar a qualidade da informação contábil das organizações, é por meio do disclosure voluntário. O disclosure voluntário é a divulgação de informações que excede o que é recomendado pela lei e representa uma escolha livre (free choice) por parte dos gestores em divulgar informações adicionais para o processo decisório dos usuários (MEEK, ROBERTS e GRAY, 1995). A evidenciação voluntária de informações permite agregar valor às organizações, dando maior credibilidade destas empresas ao mercado de capitais (ALENCAR, 2007).

Contudo, algumas empresas optam por divulgar apenas informações que apresentem vantagens para as mesmas. De acordo com Yamamoto e Salotti (2006), os níveis de divulgação podem ser afetados por diversos fatores externos à empresa, como: o ambiente em que a empresa se insere, o nível de exigência dos usuários da informação, a expectativa de lucros dos usuários, a possibilidade de divulgação de informação que beneficie a concorrência, entre outros fatores.

Estudos recentes apontam para algumas variáveis que influenciam as práticas de disclosure das organizações no Brasil. De acordo com Murcia (2009), são fatores determinantes do disclosure voluntário de companhias abertas no Brasil: a auditoria, o setor, a origem do controle, o nível de rentabilidade e o nível de endividamento. Costa, Goldner e Galdi (2007), explicam que a independência do Conselho de Administração, o tamanho da empresa, a listagem de suas ações no mercado de capitais, a participação nos níveis diferenciados de governança corporativa da Bovespa e a emissão de $A D R s$, são fatores que influenciam o disclosure dos maiores bancos brasileiros.

Cruz e Lima (2010) investigaram a relação entre a reputação corporativa e o nível de disclosure das organizações. Os resultados encontrados sugerem que as empresas de capital aberto no Brasil que possuem forte reputação fornecem aos stakeholders uma quantia significativamente maior de disclosure voluntário. Segundo Michelon (2007, p. 31), isso pode estar relacionado a uma necessidade das empresas de manter a reputação.

Outro estudo realizado, com o intuito de explicar a evidenciação ambiental divulgada pelas empresas brasileiras, foi realizado por Rover et al. (2009). Os autores procuraram identificar se fatores individuais como: tamanho, rentabilidade, endividamento, empresa de auditoria, sustentabilidade, internacionalização e publicação do relatório de sustentabilidade, influenciam o disclosure ambiental das organizações. Os resultados encontrados evidenciaram que as variáveis de tamanho da empresa, sustentabilidade, empresa de auditoria e relatório de sustentabilidade são relevantes.

Neste contexto, pode-se verificar que vários são os fatores que influenciam o disclosure das organizações brasileiras. Logo, torna-se oportuno investigar se estes fatores também interferem no processo de convergência das organizações, em especial, a adoção das Normas Internacionais de Contabilidade - IFRS (Lei 11638/2007 e CPC 13 e 37R1), em empresas públicas e privadas do setor elétrico. 


\subsection{O disclosure discricionário e sua relação com a divulgação das informações}

Conforme estudos analisados anteriormente, alguns benefícios podem resultar da divulgação voluntária de informações, por outra via, outros pesquisadores submetem a divulgação às motivações organizacionais (endógenas), também chamados de DiscretionaryBased Disclosure (baseada em julgamento).

Tais pesquisas buscam entender quais condições/motivos determinam a divulgação da informação pela administração das organizações. Para Verrechia (2001) existe um ponto denominado threshold level of disclosure (ponto de equilíbrio), que é obtido quando as percepções do mercado sobre o conteúdo das informações retidas são compatíveis com a motivação dos administradores em reter tais informações. Dobler (2005) cita três explicações que justificam a não divulgação de informação pelas organizações, sendo: a não existência de informação a ser divulgada; a ignorância dos gestores acerca da informação; e a ciência do gestor sobre a informação, porém, este possui incentivos para não divulgá-los, passando primeiramente pelo crivo sobre as consequências da divulgação da informação.

Os custos associados à divulgação compõem uma variável importante na divulgação da informação discricionária, especialmente os custos proprietários (proprietary costs), pois determinadas informações divulgadas podem ser utilizadas de maneira não favorável à empresa. Para Leuz e Wysocki (2008) estes são custos em que a companhia incorre decorrente de informações que podem ser utilizadas por outras partes como concorrentes, podendo gerar perda de vantagem competitiva.

Alguns estudos, como os de Sengupta (1998) e Botosan (1997), sugerem ainda que os administradores divulgam informações conforme suas conveniências. Ainda segundo Verrechia (2001) os gestores são racionais, e na possibilidade de disclosure não obrigatório, não divulgarão informações que possam prejudicar a si próprios ou à entidade.

$\mathrm{Na}$ literatura alguns estudos buscaram entender os fatores que influenciam a divulgação discricionária: Dye (2001) estudou os incentivos que os gestores possuem para divulgar uma informação; Guay e Verrechia (2007) comentam que o gestor irá agir estrategicamente de acordo com seu próprio interesse, o que pode resultar somente na divulgação de informações boas a respeito das empresas e a não divulgação de informações ruins.

Se de um lado estudos apontam a racionalidade dos gestores, de outro, há a hipótese da racionalidade dos investidores. Dye (1985) cita que os investidores preferem gerentes que adotam políticas desenhadas para aumentar o valor de mercado de suas ações. Esta descrição remete à possibilidade dos acionistas firmarem contratos de incentivo para que os gestores divulguem somente informações favoráveis ao valor da firma.

A divulgação discricionária, teoria ainda em fase de consolidação e conhecimento, é impactada por diversos fatores endógenos, que variam de acordo com as características de cada organização, setor ou dos gestores. Desta forma, busca-se com este trabalho analisar a divulgação nas empresas públicas e privadas do setor de energia elétrica com a teoria em tela, na expectativa de encontrar outros tipos de incentivos que também impactam sua divulgação. 


\subsection{Mudanças na evidenciação contábil brasileira a partir da convergência às normas internacionais de contabilidade}

O atual cenário de convergência contábil mundial impacta o nível da informação divulgada pelos países signatários, que deverão adequar-se às normas internacionais definidas pelo IASB (International Accountant Standarts Board). Este processo possivelmente não alcançará uma total similaridade entre os padrões contábeis dos países, porém representa um avanço harmonioso capaz de criar uma linguagem contábil apta a reduzir a assimetria contábil internacional.

Para Amenábar (2001) a harmonização significa que diferentes padrões podem existir em diferentes países, desde que estejam em harmonia com a norma internacional. Niyama (2005) comenta que os sistemas contábeis dos países são influenciados por um conjunto de regras próprias, como leis, filosofias, procedimentos e objetivos. Nesse sentido verifica-se que os desafios da harmonização são mais amplos que simples mudanças legais.

O sistema contábil de um país é influenciado por diversos fatores socioculturais. Nobes e Parker (2006) relatam que países de influência anglo-americana enfatizam o direito consuetudinário (common law), cujos princípios velam pela ética individual, estado com pouca interferência no sistema, forte mercado de capitais, reconhecimento da profissão contábil e foco nos investidores. No modelo euro-continental, no qual se inclui o Brasil, prevalece o direito formalista (code law), com características de corporativismo, prevalência dos objetivos fiscais do Estado, baixo nível de reconhecimento da profissão contábil, predominância do financiamento bancário ao mercado de capitais e resultado contábil voltado para credores e fisco.

Lemes e Silva (2007) descrevem que o processo de convergência brasileira iniciou-se pela criação do Novo Mercado em 2000, cujas exigências dentre outras obrigam a apresentação da contabilidade de acordo com um padrão internacional. No campo normativo o processo de convergência iniciou-se pela publicação das Leis 11.638/2007, 11.941/2009 e os pronunciamentos do CPC - Comitê de Pronunciamentos Contábeis.

Diante deste cenário, busca-se ainda em caráter exploratório analisar e mensurar os reflexos na qualidade da divulgação da informação contábil após o início do processo de convergências no Brasil. Segundo a PWC (2010) alguns impactos são:

a) o alcance da consistência no entendimento e aplicação das normas, devido estas serem baseadas em princípios, exigindo dos profissionais contadores maior nível de julgamento sobre o valor dos eventos econômicos;

b) maior volatilidade nos resultados, mediante a análise do valor justo de instrumentos financeiros e outras variáveis econômicas que impactam o valor econômico dos itens patrimoniais;

c) aumento do volume de informações divulgadas, especialmente para transcrever as políticas contábeis, impairment e informações por seguimento para companhias abertas; e,

d) dificuldades no reconhecimento de receitas de determinados setores, como o agropecuário, construção civil, imobiliário e outros. 
Fatores de caráter social, legal, político, cultural e outros que ainda venham a ser pesquisados também influenciam o processo de convergência, porém, não serão objetos de análise neste trabalho, podendo servir de base para futuras pesquisas.

\section{TÉCNICA PARA TRATAMENTO DOS DADOS E HIPÓTESES DA PESQUISA}

\subsection{Teoria dos conjuntos aproximativos}

Para o tratamento dos dados, a fim de se alcançar o objetivo de identificar dentro de um conjunto de características da empresa aquelas que melhor explicam a aderência às normas internacionais de empresas do Setor Elétrico listadas na BM\&F Bovespa, optou-se pela utilização de uma técnica de mineração de dados da Teoria dos Conjuntos Aproximativos (TCA). Esta teoria permite estabelecer o núcleo declaratório contábil que melhor explica a adoção das normas internacionais de contabilidade.

Esta técnica de mineração de dados foi apresentada inicialmente por Pawlak em 1982 que "introduziu a teoria dos conjuntos aproximativos como uma extensão da teoria dos conjuntos, para o estudo de sistemas inteligentes caracterizados por informações insuficientes e incompletas" (JUNIOR e COSTA, 2002). De acordo com Pinto (2008, p. 64), "por ser uma ferramenta Data Mining (mineração de dados), a TCA possui aplicações nos mais diversos campos do conhecimento, destacando-se os sistemas de apoio à decisão e em sistemas gerenciais de informação". Nesse sentido Assaf Neto e Bonízio (2001) ressaltam que "existem diversos usuários com interesses distintos da análise de demonstrações contábeis, devendo ser direcionada aos interesses daqueles que se utilizarão dela".

Segundo Gomes, Gomes e Almeida (2009), citado por Ramos (2010), a TCAé importante para as seguintes situações:

a) avaliar a importância de critério particular;

b) eliminar redundâncias em uma tabela de decisão;

c) determinar regras que diminuam uma tabela de decisão;

d) avaliar conflitos de opiniões entre especialistas;

e) representar um conhecimento ambíguo;

f) representar conhecimentos adquiridos de forma empírica;

g) caracterizar objetos de acordo com critérios e/ou atributos;

h) tratar informações qualitativas e quantitativas.

Pawlak (1982) descreve em seu trabalho a forma como ocorre o funcionamento do processo de mineração de dados. Inicialmente descreve-se uma Matriz de informação, onde as linhas são os experimentos ou objetos da pesquisa e as colunas descrevem as variáveis coletadas ou atributos. A Tabela 1 descreve o modelo da tabela de dados desenvolvida por Pawlak (1982). 
Tabela 1: Estrutura de uma Matriz de Informação

\begin{tabular}{c|c|c|c|c}
\hline & Atributo 1 & Atributo 2 & $\cdots$ & Atributo j \\
\hline Objeto 1 & $\mathrm{v}_{11}$ & $\mathrm{v}_{12}$ & $\cdots$ & $\mathrm{v}_{1 \mathrm{j}}$ \\
\hline Objeto 2 & $\mathrm{v}_{21}$ & $\mathrm{v}_{22}$ & $\cdots$ & $\mathrm{v}_{2 \mathrm{j}}$ \\
\hline$\cdots$ & $\vdots$ & $\vdots$ & $\ddots$ & $\vdots$ \\
\hline Objeto i & $\mathrm{v}_{\mathrm{i} 1}$ & $\mathrm{v}_{\mathrm{i} 2}$ & $\cdots$ & $\mathrm{v}_{\mathrm{ij}}$ \\
\hline
\end{tabular}

Fonte: Pawlak e Slowinski (1994)

A análise a luz da Teoria dos Conjuntos Aproximativos, é realizada utilizando o conjunto de opções descritas pelos atributos (no caso deste estudo os índices contábeis), comparando os objetos (empresas analisadas) entre si. Assim é possível descrever quais os índices contábeis melhor explicam à aderência as normas internacionais de contabilidade.

Observando-se a teoria apresentada, torna-se oportuno destacar alguns estudos que aplicaram a teoria dos conjuntos aproximativos na área de contabilidade. Ramos, Machado, Costa (2003), realizaram um estudo com a aplicação da teoria dos conjuntos aproximativos (TCA) no âmbito de problemas da avaliação da qualidade em serviços, no qual demonstraram que esta teoria é capaz de elaborar um grau de coerência ou qualidade em um sistema de informação para a avaliação de qualidade de serviços.

Pereira, Gómez, López (2008), aplicaram a TCA na previsão do fracasso empresarial. Neste estudo os autores elaboraram um modelo de previsão empresarial com empresas portuguesas de diferentes indústrias, que apresentassem dados econômicos, do período de 2000 a 2002, incluindo indústrias do setor têxtil, vestuário, confecção, madeira, cortiça, calçado, couro, plásticos, moldes, vidro, cutelaria e cerâmicas. Para tal utilizaram alguns indicadores, definidos como (Disponibilidades + Créditos a Curto Prazo) / Passivo a Curto Prazo, Resultado líquido/Capital Próprio e Resultados Operacionais/Ativo Total. Da amostra constituída por 818 empresas, foram consideradas 742 saudáveis ou não fracassadas e 76 fracassadas.

Hein, Pinto, Bonelli (2008), realizaram uma pesquisa com o objetivo de verificar o núcleo declaratório contábil que permite determinar o estado de solvência das empresas do ramo têxtil listadas na Bovespa, através de uma metodologia descritiva por meio de análise documental, com abordagem quantitativa dos dados e de corte transversal. Os autores concluíram que não é necessária a análise dos doze índices utilizados no estudo para chegar-se a constatação de que uma empresa é solvente ou insolvente, bastando-se analisar apenas nove destes indicadores, os quais compõem o núcleo declaratório contábil.

Desta forma, verifica-se que por meio da utilização desta técnica de tratamento de dados, torna-se possível a identificação de quais dos índices utilizados na pesquisa, conseguem melhor explicar a adoção das normas internacionais das empresas objeto de estudo.

\subsection{Hipóteses da pesquisa}

Com base na análise dos indicadores contábeis utilizados nos estudos já mencionados na introdução e fundamentação teórica dessa pesquisa, especificamente os índices utilizados por Murcia (2009), Rover et al. (2009) e Lima et al. (2010), foram determinadas as variáveis investigadas no estudo. São estas: Origem do Controle, Tamanho, Necessidade de Financiamento, 
Endividamento Total, Imobilização do Patrimônio Líquido Rentabilidade do Patrimônio Líquido.

Como descrito na contextualização da Teoria dos Conjuntos Aproximativos, busca-se por meio destas variáveis, explicar a adoção dos novos dispositivos relacionados à adoção das normas internacionais de contabilidade. Foram adotas o grau de aderência ás normas internacionais como atributo de decisão e os indicadores descritos acima como atributos de condição do modelo proposto inicialmente por Pawlak (1982).

Neste contexto, tendo em vista os achados encontrados em estudos anteriores, estabeleceram-se duas hipóteses a serem testadas na pesquisa, essências para o estudo e estimuladas pela revisão da literatura. São elas:

H1 - Os indicadores de Origem do Controle, Tamanho, Necessidade de Financiamento, Endividamento Total,Imobilização do Patrimônio Líquidoe Rentabilidadedo PatrimônioLíquido, permitem explicar a aderência de empresas do setor elétrico as normas internacionais.

Nesta perspectiva, Tarca, Moy e Morris (2005) examinaram a relação entre uso de padrões contábeis internacionais e a origem de financiamento das companhias alemãs. De acordo com os autores, os resultados sustentam a hipótese de que as companhias que utilizam financiamentos de terceiros tendem a utilizar os padrões IAS ou US GAAP. Gassen e Sellhorn (2006) analisaram os determinantes da adoção voluntária do IFRS em companhias alemãs. Por meio de testes estatísticos aplicados numa amostra total de 708 companhias no período de 1993 a 2005, os resultados revelaram que o tamanho, a exposição internacional, a dispersão da propriedade e recentes IPOs (ofertas públicas de ações), são importantes variáveis na determinação e adoção voluntária do IFRS. No Brasil, segundo Lima et. al. (2010, p. 13), empresas (i) maiores, (ii) mais expostas ao mercado internacional e (iii) que possuem maiores necessidades de financiamento são mais propensas a adotarem os novos dispositivos, de forma que perfaçam mudanças materiais nas suas políticas contábeis, em relação àquelas que não possuem os mesmos incentivos.

H2 - É possível estabelecer um núcleo declaratório contábil, que melhor explique a aderência às normas internacionais por empresas do setor elétrico, considerando os indicadores de Origem do Controle, Tamanho, Necessidade de financiamento, Endividamento total, Imobilização do patrimônio líquido e Rentabilidade do Patrimônio líquido.

De acordo com Pawlak (1982), a aplicação da teoria dos conjuntos aproximativos permite ao pesquisador, a identificação de um núcleo declaratório que melhor explique os fatos observados. Neste caso, os fatores que explicam a adoção voluntária pelas empresas pesquisadas às normas internacionais de contabilidade. A refutação de alguma destas hipóteses ou de ambas implica na aceitação da hipótese nula das mesmas.

\section{MÉTODO E PROCEDIMENTOS DA PESQUISA}

Este estudo caracteriza-se como uma pesquisa exploratória, com abordagem quantitativa dos dados. De acordo com Lakatos e Marconi (2006, p. 85), a pesquisa exploratória “é utilizada para realizar um estudo preliminar do principal objetivo da pesquisa que será realizada, ou seja, familiarizar-se com fato ou fenômeno que está sendo investigado, de modo que a pesquisa subseqüente possa ser realizada com maior compreensão, clareza e precisão". 
Inicialmente realizou-se uma pesquisa bibliográfica, com o intuito de fundamentar o estudo proposto. "A pesquisa bibliográfica é desenvolvida com base em material já elaborado, constituído principalmente de livros e artigos científicos" (Gil, 2002, p. 44). A seguir, uma pesquisa documental, onde se buscou junto ao sitio da BM\&F Bovespa os dados necessários para o estabelecimento da população objeto de estudo.

A população em questão refere-se às empresas de capital aberto do setor de eletricidade (geração e distribuição), que negociavam ações na BM\&F Bovespa em janeiro de 2011. Ao todo foram identificadas 65 organizações neste setor.

O período objeto de estudo refere-se aos relatórios contábeis do exercício de 2008, publicados em 2009. Para a coleta e análise dos dados procurou-se identificar apenas as empresas que disponibilizaram as demonstrações contábeis consolidadas. Assim sendo, verificou-se que 35 empresas não apresentaram esta categoria de informação. Sendo assim, foram utilizadas para a análise da pesquisa as demonstrações contábeis obrigatórias e consolidadas de 30 empresas do setor elétrico, sendo sete estatais e 23 privadas.

\subsection{Variáveis de investigação e o índice de observância às práticas de convergência}

\subsubsection{Fatores que influenciam o disclosure das organizações}

Este item apresenta as variáveis que foram testadas na pesquisa, a fim de identificar se estas influenciam ou não no disclosure das organizações, em relação à adoção das práticas contábeis internacionais, estabelecidas pela Lei 11.638/2007 e os Pronunciamentos Contábeis do CPC (CPC 13 e 37 R1).

No trabalho de Lima et al. (2010), os resultados apresentados, descrevem que empresas com maior tamanho e com maior necessidade de financiamento tendem a possuir um nível de disclosure maior do que as demais empresas. A variável tamanho é corroborada pelo estudo de Rover et al. (2009). Murcia (2009) destaca, dentre os fatores que afetam o disclosure, a questão da origem controle, se estatal ou privado, do nível de rentabilidade da empresa e de seu endividamento.

Nesta perspectiva, para a realização deste estudo, foram adotados os índices de Tamanho das empresas, por meio do ativo total, bem como Tipo de controle (privado ou estatal), Necessidade de Financiamento, Endividamento Total, Imobilização do Patrimônio Líquido e Rentabilidade do Patrimônio Líquido. A utilização destes indicadores justifica-se por estes já serem utilizados em estudos anteriores que buscam explicar o disclosure das organizações, o que permite a comparação dos achados da pesquisa.

\subsubsection{Métrica do índice de observância às práticas de convergência (IOPC)}

Para que fosse possível concluir sobre o objeto de estudo, adotou-se o Índice de Observância às Práticas de Convergência (IOPC) utilizados por Lima et al. (2010). A métrica sugerida na pesquisa, leva em consideração as recomendações da Lei 11.638/2007, para adoção inicial das IFRS, bem como do Pronunciamento Técnico CPC n ${ }^{\circ} 13$. O Quadro 2 apresente os itens observados na pesquisa. 


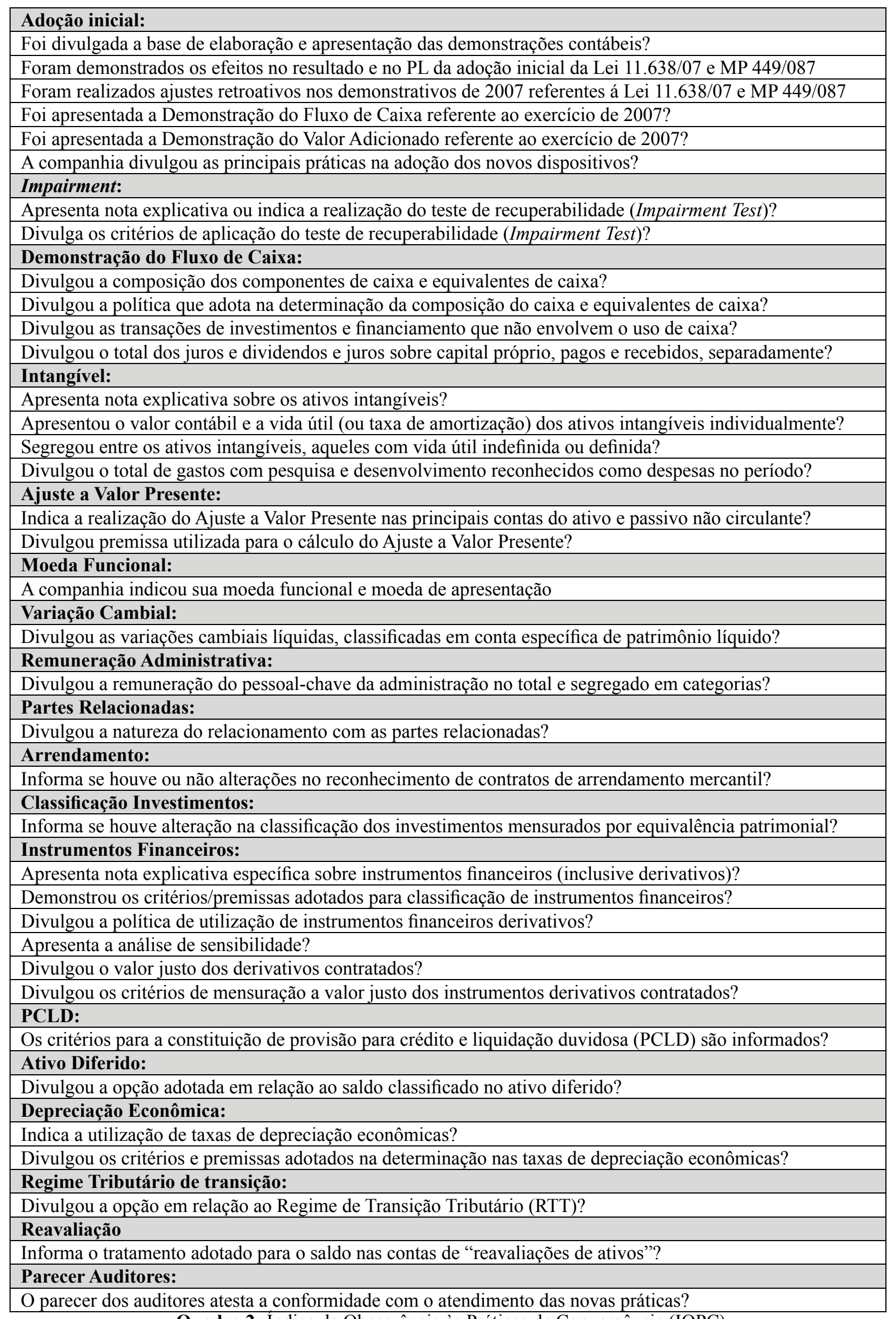

Quadro 2: Indice de Observância às Práticas de Convergência (IOPC)

Fonte: Lima et al. (2010) 
Lima et al. (2010, p. 11) explicam que o IOPC “é um índice auto construído composto por 37 perguntas binárias (" 1 " caso afirmativo e " 0 " se negativo) relacionadas às práticas de convergência aos padrões IFRS, instituído no Brasil pelas Leis $n^{\circ} .11 .638 / 07,11.941 / 09$ e os novos pronunciamentos do Comitê de Pronunciamentos Contábeis (CPC)". Os resultados da pesquisa são apresentados a seguir.

\section{ANÁLISE E INTERPRETAÇÃO DOS RESULTADOS DA PESQUISA}

O Quadro 3 descreve o índice de aderência das empresas analisadas e qual a Origem de Controle das organizações. O Percentual de aderência identificado na pesquisa se refere ao grau de evidenciação das empresas analisadas, segundo os índices descritos pelo IOPC.

\begin{tabular}{|cllcllll|}
\hline & Empresa & Controle & $\begin{array}{c}\text { \% } \\
\text { Aderência } \\
\text { as IFRS }\end{array}$ & & Empresa & Controle & $\begin{array}{c}\% \\
\text { Aderência } \\
\text { as IFRS }\end{array}$ \\
\hline 1 & CEB & Estatal & $47,2 \%$ & 16 & CPFL GERACAO & Privada & $94,4 \%$ \\
\hline 2 & CELESC & Estatal & $63,9 \%$ & 17 & ENERGIAS BR & Privada & $77,8 \%$ \\
\hline 3 & CELGPAR & Estatal & $55,6 \%$ & 18 & ENERGISA & Privada & $72,2 \%$ \\
\hline 4 & CEMIG & Estatal & $91,7 \%$ & 19 & EQUATORIAL & Privada & $77,8 \%$ \\
\hline 5 & CEMIG GT & Estatal & $91,7 \%$ & 20 & FORPART & Privada & $38,9 \%$ \\
\hline 6 & COPEL & Estatal & $75,0 \%$ & 21 & IENERGIA & Privada & $50,0 \%$ \\
\hline 7 & ELETROBRAS & Estatal & $80,6 \%$ & 22 & LIGHT S/A & Privada & $77,8 \%$ \\
\hline 8 & 521 PARTICIP & Privada & $88,9 \%$ & 23 & MPX ENERGIA & Privada & $77,8 \%$ \\
\hline 9 & AES ELPA & Privada & $72,2 \%$ & 24 & NEOENERGIA & Privada & $66,7 \%$ \\
\hline 10 & AES TIETE & Privada & $72,2 \%$ & 25 & REDE ENERGIA & Privada & $69,4 \%$ \\
\hline 11 & AGCONCESSOES & Privada & $83,3 \%$ & 26 & TERNA PART & Privada & $38,9 \%$ \\
\hline 12 & AMPLA INVEST & Privada & $61,1 \%$ & 27 & TRACTEBEL & Privada & $61,1 \%$ \\
\hline 13 & BONAIRE PART & Privada & $88,9 \%$ & 28 & TRAN PAULIST & Privada & $66,7 \%$ \\
\hline 14 & BRASILIANA & Privada & $72,2 \%$ & 29 & UPTICK & Privada & $47,2 \%$ \\
\hline 15 & CPFL ENERGIA & Privada & $94,4 \%$ & 30 & VBC ENERGIA & Privada & $69,4 \%$ \\
\hline
\end{tabular}

Quadro 3: Aderência as normas Internacionais.

Fonte: dados da Pesquisa

É possível observar no Quadro 3 que nenhuma empresa aderiu totalmente às normas internacionais (100\%) no período analisado. Dentre as empresas pesquisadas, se destacam duas empresas do setor privado, a CPFL Energia e a CPFL Geração, que são as empresas que mais aderiram às normas internacionais, com um percentual de atributos atendidos igual a $94,4 \%$ dos itens observados em ambas as organizações. Especificamente relacionado a empresas do setor público, as que evidenciaram maior propensão à adoção dos novos dispositivos legais foram a CEMIG e CEMIG GT.

Em contrapartida, as empresas que evidenciaram o menor nível de adoção dos novos dispositivos contábeis, dentre as analisadas, foram a Forpart e a Terna Part., ambas do setor privado, com percentual de aderência de apenas $38,9 \%$ dos itens investigados na pesquisa.

Em termos gerais, no período objeto de estudo, pode-se verificar, por meio das médias gerais resultantes da análise do IOPC das empresas pesquisadas (Quadro 3), que as empresas 
privadas do setor elétrico, tiveram maior propensão a adesão dos dispositivos recomendados na legislação neste período. O percentual médio de adesão destas empresas foi de $77,10 \%$, enquanto as empresas do setor público apresentaram uma média inferior (72,24\%).

A Tabela 2 apresenta os resultados evidenciados pela TCA no teste para encontrar o núcleo declaratório das informações que melhor explicam a adoção dos novos dispositivos. Esta descreve as combinações que obtiveram melhor resultado na descrição dos níveis de adoção das normais internacionais pelas empresas do setor elétrico, considerando as variáveis investigadas na pesquisa.

Tabela 2: Resultado das combinações da TCA

\begin{tabular}{c|c|c|c|c|c}
\hline \multirow{2}{*}{$\begin{array}{c}N^{o} \text { de } \\
\text { Índices }\end{array}$} & Combinações & \multicolumn{2}{|c|}{ Precisão da Aproximação } & Qualidade da \\
\cline { 2 - 5 } & Alta & Média & Baixa & Aproximação \\
\hline 6 & Controle, Tamanho, NCdeFIN, END_Tot, IPL, RPL & 0,846 & 0,750 & 0,600 & 0,867 \\
5 & Tamanho, NCdeFIN, END_Tot, IPL, RPL & 0,846 & 0,750 & 0,600 & 0,867 \\
4 & Tamanho, NCdeFIN, IPL, RPL & 0,714 & 0,647 & 0,600 & 0,800 \\
3 & Tamanho, END_Tot, RPL & 0,389 & 0,474 & 0,167 & 0,567 \\
2 & NCdeFIN, END_Tot & 0,087 & 0,111 & 0,077 & 0,200 \\
1 & Tamanho & 0 & 0 & 0 & 0 \\
\hline
\end{tabular}

Fonte: elaborado pelos autores.

Analisando-se a Tabela 2 é possível identificar que com os seis índices objetos de estudo, a qualidade da aproximação foi igual a $86 \%$ de explicação. Já se forem considerados apenas os índices de "Tamanho, Necessidade de Financiamento, Endividamento Total, Imobilização do Patrimônio Líquido e Rentabilidade do Patrimônio Líquido", essas cinco variáveis possuem a mesma qualidade de explicação da aderência.

De acordo com Pawlak (1982), a TCA permite a análise do menor número de variáveis que possuem maior peso na discriminação do atributo de decisão, neste caso o grau de aderência as normas internacionais. Nesta perspectiva, observa-se na Tabela 2 que, com a utilização de apenas quatro ("Tamanho, Necessidade de Financiamento, Imobilização do Patrimônio Líquido e Rentabilidade do Patrimônio Líquido") dos seis índices pesquisados, ainda é possível se obter uma alta qualidade de aproximação (80\%) na explicação da aderência dessas empresas as normas internacionais de contabilidade.

Também se procurou investigar o quanto cada índice explica individualmente à aderência as normas internacionais. Esta análise permite descrever qual dos índices melhor explica à aderência aos novos dispositivos legais. Dentre os índices analisados individualmente é possível descrever que nenhum possibilita a análise da aderência aos itens do IOPC. Individualmente, todos auferiram $0 \%$ na previsão dos graus de aderência e $0 \%$ na qualidade de aproximação da previsão. Estes resultados evidenciam que não é possível explicar o disclosure das organizações apenas com um índice específico, mas sim, com um conjunto de indicadores, como os utilizados na pesquisa.

O método da TCA apresenta ainda qual é o núcleo declaratório contábil na predição da aderência às normas internacionais. Este núcleo é composto do(s) atributo(s) de condição que melhor explica $(m)$ o atributo de predição e que são mais coerentes em seus valores, no caso deste estudo, destaca-se o índice de aderência às normas contábeis internacionais como fator 
de aderência. Para tanto os resultados apresentam o conjunto Núcleo $=\{$ Tamanho, Necessidade de Financiamento, Endividamento Total, Imobilização do Patrimônio Líquido e Rentabilidade do Patrimônio Líquido\}, os cinco índices, destacados foram os que juntos possuem o melhor desempenho na descrição do grau de aderência as normas internacionais de contabilidade.

Os resultados encontrados corroboram com as pesquisas de Lima et al. (2010) e Rover et al. (2009), onde descreveram que os índices do Tamanho e Necessidade de Financiamento estão entre os índices que melhor explicam a aderência as normas internacionais. Em paralelo ao trabalho de Murcia (2009), os fatores de rentabilidade e endividamento afetam o disclosure das empresas. Este achado também foi confirmado no presente estudo. Em contraponto, no caso analisado, a variável de Controle não se apresentou como fator determinante no disclosure das empresas analisadas, ou seja, é indiferente a empresas ter controle privado ou estatal quando se busca descrever seu grau de aderência as normas internacionais.

Desta forma confirmam-se a hipótese H1 que descreve a possibilidade de explicar o grau de aderência as normas internacionais por meio dos indicadores tomados para o estudo. Este fato se confirma por estes indicadores definirem aproximadamente $86 \%$ da informação que explica a aderência destas empresas. Também foi possível estabelecer um núcleo declaratório contábil por meio da TCA, o que permite aceitar também a hipótese $\mathrm{H} 2$, que descreve a possibilidade de estabelecer o núcleo declaratório contábil. Com a confirmação de tal hipótese os índices de Tamanho, Necessidade de Financiamento, Endividamento Total, Imobilização do Patrimônio Líquido e Rentabilidade do Patrimônio Líquido, forma o conjunto de índices que melhor evidenciam a aderência as IFRS nas empresas em estudo.

\section{CONSIDERAÇÕES FINAIS}

Este estudo buscou analisar os fatores que determinam a adoção do processo de convergência contábil nas empresas do setor elétrico. $O$ foco do trabalho está na investigação dos fatores que podem influenciar a divulgação dessas informações no mercado de capitais.

O objetivo central do estudo foi identificar dentro de um conjunto de características da empresa aquelas que melhor explicam a aderência às normas internacionais de empresas do Setor Elétrico listadas na BM\&F Bovespa. As características investigadas no estudo foram: Origem de Controle, Tamanho, Necessidade de Financiamento, Endividamento Total, Imobilização do Patrimônio Líquido e Rentabilidade do Patrimônio Líquido.

A metodologia utilizada na pesquisa caracterizou-se como um estudo exploratório, com abordagem quantitativa dos dados. Para a conclusão do objeto em estudo, adotou-se o Índice de Observância às Práticas de Convergência (IOPC), propostos por Lima et al. (2010), construído a partir do estabelecimento dos novos dispositivos legais (Leis 11.638/2007, 11.641/2009 e os novos pronunciamentos do Comitê de Pronunciamentos Contábeis (CPC 13 e 37 R1).

Foram analisadas as demonstrações contábeis obrigatórias e consolidadas de 30 empresas de capital aberto do setor de eletricidade (geração e distribuição), sendo sete estatais e 23 privadas, que negociavam ações na BM\&F Bovespa em janeiro de 2011. O período objeto de estudo refere-se aos relatórios contábeis do exercício de 2008, publicados em 2009. 
A partir do estabelecimento do IOPC, procurou-se investigar se características, como a Origem de controle, Tamanho, Necessidade de Financiamento, Endividamento Total, Imobilização do Patrimônio Líquido e Rentabilidade do Patrimônio Líquido, influenciam a adoção ou não das IFRS, nas empresas pesquisadas. Os resultados encontrados indicam que, no período objeto de estudo, empresas privadas do setor elétrico tiveram maior propensão a adesão dos dispositivos legais, do que empresas públicas do mesmo setor.

Em relação às hipóteses estabelecidas na pesquisa, a hipótese $\mathrm{H} 1$ foi aceita, tendo em vista que o conjunto de indicadores investigados na pesquisa permite explicar em aproximadamente $86 \%$ a aderência dessas empresas às normas internacionais de contabilidade. Da mesma forma aceitou-se a segunda hipótese estabelecida no estudo (H2), descrevendo-se a existência de um núcleo declaratório nos dados analisados.

As características que mais explicam a adoção aos novos dispositivos legais nas empresas pesquisadas foram: Tamanho, Necessidade de Financiamento, Endividamento Total, Imobilização do Patrimônio Líquido e Rentabilidade do Patrimônio Líquido (RPL). A origem do controle das empresas (estatal ou privada) não fez parte do núcleo da informação contábil, quando da aderência às normas contábeis internacionais, o que indica que, neste caso, esta variável não explica a adoção das empresas pesquisadas aos novos dispositivos legais.

Individualmente nenhum índice possibilitou a descrição da aderência destas empresas as IFRS, sendo significativa a análise apenas por meio de um conjunto de indicadores. Os achados da pesquisa convergem com os estudos anteriores realizados por Tarca, Moy e Morris (2005), Gassen e Sellhorn (2006) e Lima et. al. (2010). Desta forma, em resposta ao objetivo da pesquisa, verifica-se que os índices que melhor explicam a aderência às normas internacionais pelas empresas pesquisadas, são os índices pertencentes ao núcleo declaratório evidenciado na pesquisa. Como recomendação a estudos futuros, sugere-se a investigação destes itens nas demais empresas públicas e privadas de outros setores econômicos que negociam ações no mercado de capitais.

\section{REFERÊNCIAS}

AGGARWAL, R.; KLAPPER, L.; WYSOCKI, P. D. Portfolio Preferences ofForeign Institutional Investors, Journal of Banking and Finance, v. 29, p. 2919-2946, 2005.

ALENCAR, R. C. Nível de disclosure e custo de capital próprio no mercado brasileiro. 2007. 104fls. Tese (Doutorado em Ciências Contábeis) - Universidade de São Paulo, 2007.

AMENÁBAR, A. M. H. Harmonização contábil em cinco países da América do Sul. 2001. v. 1. Dissertação (Mestrado em Controladoria e Contabilidade) - Universidade de São Paulo, São Paulo, 2001.

ARMSTRONG, C. S.; BARTH, M. E.; JAGOLINZER, A. D.; RIEDL, E. J. Market Reaction to the Adoption of IFRS in Europe. The Accounting Review, v. 85, n. 1, p. 31-61, 2010.

ASSAF NETO, A.; BONIZIO, R. C. Indicadores de análise de balanços de empresas do setor de 
construção civil. Anais... São Leopoldo: VIII Congresso Brasileiro de Custos, 2001

BALL, R. International Financial Reporting Standards (IFRS): Pros and Cons for Investors. Accounting and Business Research: International Accounting Policy Forum, p. 5-27, 2006.

BALL, R.; SHIVAKUMAR, L. Earnings Quality in U.K. Private Firms. Journal of Accounting and Economics, v. 39, p. 83-128, 2005.

BAUMANN, U.; NIER, E. Disclosure, Volatility, and transparency: an empirical investigation into the value of bank disclosure. Economic Policy Review - Federal Reserve Bank of New York. vol. 10. n. 2. p. 31-45. sep. 2004.

BOTOSAN, C. Disclosure level and cost of equity capital. The Accounting Review, v. 72, p. 323-349, 1997.

BRADSHAW, M. T.; BUSHEE, B. J.; MILLER, G. S. Accounting Choice, Home Bias, and U.S. Investment in Non-U.S. Firms. Journal of Accounting Research, v. 42, p.795-841, 2004.

BRASIL. Lei $\mathrm{n}^{\mathrm{o}} 11.638$ de 28 de Janeiro de 2007. Disponível em: http://www.cvm.gov.br/ 2007. Acesso em 19 de Janeiro de 2011.

BURGSTAHLER, D. C.; HAIL, L.; LEUZ, C. The Importance of Reporting Incentives: Earnings Management in European Private and Public Firms. The Accounting Review, v. 81, p. 983-1016, 2006.

CHRISTENSEN, H. B.; LEE, E.; WALKER, M. Cross-Sectional Variation in the Economic Consequences of International Accounting Harmonization: The Case of Mandatory IFRS Adoption in the UK. International Journal of Accounting, v. 42, p. 341-379, 2007.

COSTA, F. M. da; GOLDNER, F.; GALDI, F. C. Análise dos fatores que influenciam no disclosure dos maiores bancos brasileiros. In: Congresso USP de Controladoria e Contabilidade, 7, 2007, São Paulo. Anais... São Paulo: FEA/USP, 2007. CD-ROM.

COVRIG, V. M.; DEFOND, M. L.; HUNG, M. Home Bias, Foreign Mutual Fund Holdings, and the Voluntary Adoption of International Accounting Standards. Journal of Accounting Research, v. 45, p. 41-70, 2007.

CPC - Comitê de Pronunciamentos Contábeis. Pronunciamentos Técnicos. 2011. Disponível em http://www.cpc.com.br/ 2011. Acesso em 15 de Fevereiro de 2011.

CRUZ, C. V. O. A.; LIMA, G. A. S. F. de. Reputação corporativa e nível de disclosure das empresas de capital aberto no Brasil. Universo Contábil, v. 6, n. 1, jan/mar, 2010, p. 85-101.

CVM - Comissão de Valores Mobiliários. Instruções e Deliberações. Disponível em: http://

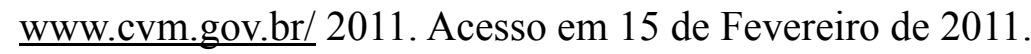

DANTAS, J. A.; ZENDERSKY, H. C.; NIYAMA, J. K. A dualidade entre os benefícios do disclosure e a relutância das organizações em aumentar o grau de evidenciação. In: ENANPAD, 28, 2004, Curitiba. Anais... Rio de Janeiro: ANPAD, 2004. CD-ROM.

DASKE, H.; HAIL, L.; LEUZ, C.; VERDI, R.. Adopting a Label: Heterogeneity in the Economic 
Consequences of IFRS Adoptions. Working Paper, University of Pennsylvania and University of Chicago, 2009.

DOBLER. M. Howinformative is riskreporting? Areview of disclosure models. Munich Business Research Working Paper. Social Science Research Network. Disponível em <www,ssrn. com> 2005. Acesso em 02 de Janeiro de 2011.

DYE, R. Disclosure of non proprietary information. Journal of Accounting and Economics, v. 23, p. 123-145, 1985.

. An evaluation of 'essays on disclosure' and the disclosure literature in accounting. Journal of Accounting and Economics, v. 32, p. 181-235, 2001.

GASSEN, J.; SELLHORN, T. Applying IFRS in Germany - determinants and consequences. 2006. Disponível em: www.ssrn.com. Acesso em: 29 Jul. 2011.

GIL, A. C. Como elaborar projetos de pesquisa. 4.ed. São Paulo: Atlas, 2002.

GUAY, W.; VERRECHIA, R. Conservative disclosure. Social Science Research Network. Disponível em: www.ssrn.com. 2007. Acesso em 02 de Janeiro de 2011.

HAIL, L.; LEUZ, C.; WYSOCKI, P. Global Accounting Convergence and the Potential Adoption of IFRS by the United States: An Analysis of Economic and Policy Factors. Working Paper, 2009.

HANDA, P.; LINN, S. C. Arbitrage pricing with estimation risk. Journal of Financial and Quantitative Analysis. v. 28. n. 1. p. 81-100. Mar. 1993.

HEALY, P. M.; PALEPU, K. G. Information asymmetry, corporate disclosure, and the capital markets: a review of the empirical disclosure literature. Journal of Accounting and Economics. vol. 31. p. 405-440. 2001.

HEIN, N.; PINTO, J.; BONELLI, G. G. Uma ferramenta Data Minig na análise de solvência de empresas do setor têxtil. SPOLM 2008, ISSN 2175-6295, 2008.

IASB - International Accounting Standarts Board. Normas Internacionais de Contabilidade 2001: texto completo de todas as normas internacionais de contabilidade e interpretações SIC existentes em $1^{\circ}$ de Janeiro de 2001. São Paulo: Ibracon, 2001.

JUNIOR, H. P. G. S.; COSTA H. G. Utilização dos conjuntos aproximativos e da lógica Fuzzy como instrumentos de apoio na de mensuração do grau dos riscos. Anais... ENEGEP 2002.

LAKATOS, E. M.; MARCONI, M. A. Técnicas de pesquisa: planejamento e execução de pesquisas, amostragens e técnicas de pesquisa, elaboração, análise e interpretação de dados. 6 . ed. São Paulo: Atlas, 2006.

LEMES, S.; SILVA. M. G. A experiência de empresas brasileiras na adoção das IFRS. Contabilidade Vista \& Revista, UFMG, Belo Horizonte, v.18, n. 3, p. 37-58, jul./set. 2007.

LEUZ, C.; WYSOCKI, P. Economic consequences of financial reporting and disclosure regulation: A review and suggestions for future research. Social Science Research Network. 
Disponível em: www.ssrn.com 2008. Acesso em 02 de Janeiro de 2011.

LIMA, V. S.; FRANCO DE LIMA, G. A. S.; SIQUEIRA LIMA, I.; CARVALHO, L. N. G. Determinantes da convergência aos padrões internacionais de contabilidade no Brasil. Anais... ANPCONT, 2010.

MEEK, G.; ROBERTS, C.; GRAY, S. Factors influencing voluntarily annual report disclosure by U.S., U.K., and continental European multinational corporations. Journal of International Business Studies, v. 26, p. 555-572, 1995.

MICHELON, G. Sustainability disclosure and reputation: a comparative study. Università Degli Studi di Padova. Marco Fanno working paper. Sep/2007.

MURCIA, F. D. Fatores determinantes do nivel de disclosure voluntário de companhias abertas no Brasil. 2009. 181 fls. Tese (Doutorado em Ciências Contábeis) - Universidade de São Paulo, São Paulo, 2009.

NIYAMA, J. K. Contabilidade Internacional. São Paulo: Atlas, 2005.

NETO, A. A.; BONIZIO, R. C. Indicadores de análise de balanços de empresas do setor de construção civil. Anais... São Leopoldo: VIII Congresso Brasileiro de Custos, 2001.

NOBES, C. The Survival of International Differences under IFRS: Towards a Research Agenda. Accounting and Business Research, v. 36, p. 233-245, 2006.

NOBES, C.; PARKER, R. Comparative International Accounting (9th Ed), London, Prentice Hall, 2006.

PAWLAK, Z. Rough Sets. International Journal of Parallel Programming, v. 11, n. 5, p. 341356, 1982.

; SLOWINSKI, R. Decision Analysis using Rough Sets. Operational Research. v.1, n. 1. Lisboa, 1994, p. 107-114.

PEREIRA, J. M. GÓMEZ, F. D.; LÓPEZ, M. R. Aplicação da Teoria dos Rough Sets na Previsão do Fracasso Empresarial. Revista de Estudos Politécnicos (Polytechnical Studies Review) 2008, Vol VI, no 10, 199-220, 2008.

PINTO, J. Núcleo declaratório contábil na análise da solvência de empresas do setor têxtil listadas na Bovespa. 158 f. 2008. Dissertação (Mestrado em Ciências Contábeis), FURB.

PWC - PricewaterhouseCoopers. IFRS E CPCs. A nova Contabilidade brasileira: Impactos para o profissional de RI. Outubro/2010. Caderno IFRS e CPCs - A nova contabilidade brasileira.

RAMOS, M. S. Utilização da abordagem multicritério para priorização do portifólio de projetos de investimento. 150 f., 2010. Dissertação (mestrado em administração), Faculdade de Economia e Finanças- IBMEC, 2010.

RAMOS, R. R.; MACHADO, A. O.; COSTA, H. G. A Teoria dos conjuntos aproximativos na determinação do grau de coerência aplicado a um sistema de classificação para a qualidade em serviços. Anais... X SIMPEP, 2003. 
ROVER, S. et al. Explicações para a divulgação voluntária ambiental no Brasil utilizando análise de regressão em painel. In: ANPCONT, 3, 2009, São Paulo. Anais... São Paulo: ANPCONT, 2009. CD-ROM.

SCHROEDER, R. G; CLARK, M. W; CATHEY, J. M. Financial accounting: theory and analysis. 7 ed. New York: Wiley, 2001.

SENGUPTA, P. Corporate disclosure quality and the cost of debt. The Accounting Review, v. 73, p. 459-474, 1998.

SHIN, H. News management and the value of the firm. RAND Journal of Economics, v. 25, p. 58-70, 1994.

STAIR, R. M. Princípios de Sistemas de Informação: uma abordagem gerencial. Tradução de Maria Lúcia Leker Vieira e Dalton Conde de Alencar. 2. ed. Rio de Janeiro: LTC, 1998.

TARCA, A.; MOY, M.; MORRIS, R. An investigation of the relationship between use of international accounting standards and source of company finance in Germany. 2005. Disponível em <http:// www.ssrn.com>. Acesso em: 29 jul. 2011.

VERRECCHIA, R. Essays on disclosure. Journal of Accounting and Economics, v. 22, p. $97-$ $180,2001$.

YAMAMOTO, M. M.; SALOTTI, B. M. Informação Contábil: Estudos sobre a Divulgação no Mercado de Capitais. 1.ed. São Paulo: Atlas, 2006. 


\section{ENDEREÇO DOS AUTORES:}

\section{Vinícius Costas da Silva Zonatto}

Faculdade Dom Alberto.

Rua Ramiro Barcelos, 892, Centro

Santa Cruz do Sul, RS - Brasil

$96810-054$

\section{Alexandre Corrêa dos Santos}

Volponi Contadores Associados.

Av. Maringá, 627, Vitória

Londrina, PR - Brasil

86060-000

\section{Moacir Manoel Rodrigues Junior}

Fundação Universidade Regional de Blumenau.

Rua: Antônio da Veiga, 140

Blumenau, SC - Brasil

89012-120

\section{Francisco Antonio Bezerra}

Fundação Universidade Regional de Blumenau.

Rua Antonio da Veiga, 140

Victor Konder

Blumenau, SC - Brasil

$89012-900$ 